\title{
Ideologia: \\ uma breve história do conceito
}

Marcus V. Mazzari

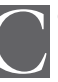
OM a publicação em 2010 do volume Ideologia e contraideologia, Alfredo Bosi se lança a um considerável desafio, o qual pode ser sintetizado na metáfora do "nó ideológico". Essa imagem se explicita no título do último ensaio, que busca desenovelar os vários fios envolvidos na trama ideológica vislumbrada na obra ficcional de Machado de Assis (em especial, nas Memórias póstumas de Brás Cubas). Mas, para enfrentar tal tarefa, é necessário antes abrir clareiras no tremedal teórico que envolve o conceito de "ideologia" e, para isso, Bosi percorre um longo itinerário, que vai às raízes da filosofia ocidental. Pois se a palavra idéologie foi cunhada em 1796 pelo pensador sensista Destutt de Tracy, a pré-história desse conceito pode ser sondada já na oposição, articulada por Platão, à atividade dos sofistas, "primeiros profissionais da retórica e do mercado ideológico que a história da filosofia registra". É claro que esse percurso pela intrincada trajetória do conceito “ideologia" não é realizado apenas em função da obra machadiana, pois na verdade todo o livro constitui um extraordinário esforço de elucidar alguns dos fios que o pensamento ocidental urdiu em "nó ideológico"; mas, chegando o leitor ao último ensaio, vários pressupostos da argumentação crítica lhe estarão suficientemente claros, refiram-se eles a concepções de Karl Mannheim, Marx e Engels, dos moralistas, ou ainda a particularidades da história do liberalismo na Europa, nos Estados Unidos e, sobretudo, no Brasil.

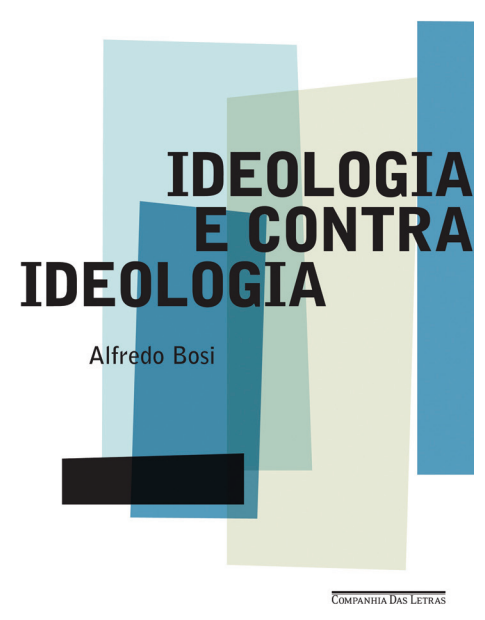

BOSI, A. Ideologia e contraideologia: temas e variações.

São Paulo: Companhia das Letras, 2010.

Impressiona, em primeiro lugar, a profusão de teóricos visitados ao longo dos 25 ensaios do livro. Em seu primeiro bloco (transpondo-se o portal de entrada "socrático-platônico") estão Francis Bacon, cuja doutrina dos "ídolos" avulta como um marco inicial na reflexão moderna sobre ideologia, assim como Montaigne e Thomas Morus. Alfredo Bosi passa em revista vários outros nomes envolvidos nos embates ideológicos dos primeiros tempos da Era Moderna, enfocando na sequência as Luzes, o período pós-revolucionário, e assim sucessivamente, até chegar a Habermas e outros contemporâneos. Contudo, a linearidade da cronologia é complexificada à medida que se criam vasos $\mathrm{co}^{-}$ 
municantes entre os ensaios, o que dá grande vivacidade ao conjunto. Desse modo, o esboço utópico de Morus retorna, acompanhado de comentários de Horkheimer, num momento posterior do livro, que destaca as circunstâncias históricas propiciadoras do advento das utopias renascentistas, sobretudo a miséria dos camponeses ingleses e italianos, que Morus e Tommaso Campanella atribuíram à ausência de limites para a propriedade privada.

$\mathrm{Na}$ impossibilidade de se deter aqui sobre cada um dos teóricos comentados, valeria ressaltar alguns momentos do amplo panorama construído pelo autor, como os capítulos dedicados ao pensamento de Rousseau, resistente às "máximas" ideológicas de seu tempo, ou de Montesquieu, que deu ênfase às ideias de "condição" e "relação" para a compreensão do "Espírito das Leis". Em outro capítulo particularmente denso, sintetizam-se linhas de força do pensamento de Vico, Condorcet e Hegel sob o prisma de três figuras: o ciclo dos fluxos (corsi) e refluxos (recorsi) na filosofia da história viquiana; a linha reta do "perfectibilismo" (termo que remonta ao Discurso sobre a desigualdade de Rousseau) no teórico do progresso Condorcet; e, ainda, a espiral dialética delineada por Hegel, espécie de linha ascendente que, voltando sobre si mesma para cumprir o seu percurso, só avança “depois de ter-se curvado, compondo uma figura que é ascendente na direção geral e, por um breve momento, parece fechar-se no seu movimento interno". Também a teoria política de John Locke é minuciosamente reconstituída por Bosi, que aponta, já nesse manancial do liberalismo inglês, a "conjugação de retórica universalizante e interesses particulares", pois afinal o teórico da tolerância teria sido ao mesmo tempo acionista da Royal African Company, e em seu esboço social a escravidão estaria legitimada enquanto "um ato de força tornado legal (a lawful conqueror) e reconhecido como pacto imemorial". Não por acaso, o segmento sobre Locke figura na segunda parte do livro, voltada às intersecções ideológicas entre Brasil e Ocidente, em cujo contexto levanta-se uma das teses centrais do livro, que ressurge no ensaio sobre Machado sustentando que o liberalismo excludente não representa uma excrescência brasileira, deslocamento aberrante de ideias europeias para o nosso contexto, mas antes "um complexo de medidas econômicas e políticas efetivas que regeram todo o Ocidente atlântico desde o período napoleônico e a Restauração monárquica francesa".

Essa observação ajuda a elucidar o desenho geral do livro: vários pontos desenvolvidos na primeira parte, que percorre momentos cruciais do pensamento ocidental, retornam na segunda, que se debruça mais especificamente sobre aspectos da história brasileira, em particular liberalismo, escravidão e luta abolicionista, ou ainda projetos trabalhistas, sobretudo sob o governo de Getulio Vargas, cuja análise se desenvolve perante o pano de fundo do Welfare State inglês e do État-Providence. O fio que alinhava esses 25 ensaios é explicitamente o conceito de ideologia, que Bosi opera em suas duas acepções, designadas por Norberto Bobbio como sentido forte e fraco. O primeiro caracteriza-se por uma dimensão por assim dizer metonímica, já que busca conferir camuflagem universal a interesses particulares, e remonta, sobretudo, à Ideologia alemã, em que Marx e Engels definem ideolo- 
gia como "falsa consciência" - também como inversão da objetividade histórica, conforme se formula nessa célebre passagem: "Se no todo da ideologia os homens e suas relações aparecerem de ponta-cabeça, como numa camera obscura, então esse fenômeno resulta do seu processo histórico de vida, do mesmo modo como a inversão dos objetos na retina resulta do imediato processo físico de vida".

Mas se o estudo de Bosi abre amplo espaço a essa obra de Marx e Engels que inaugurou nova fase na crítica ideológica, ele não dispensa menor atenção à outra acepção do termo "ideologia", na qual o qualificativo "fraco" se deve apenas à sua dimensão não valorativa, que faz jus ao sentido etimológico de "doutrina de ideias". Esse significado mais flexível, como também se pode entender o adjetivo "fraco", é tributário da sociologia do saber (Wissenssoziologie) e terá recebido sua elaboração mais consistente na obra de Karl Mannheim Ideologia e utopia (1929), que consequentemente ocupa posição de relevo na argumentação crítica de Alfredo Bosi. Nessa perspectiva, ideologia equivaleria de certo modo à "visão de mundo", ultrapassando o significado mais restrito de "falsa consciência", o que já se prefigura, como lembra o excelente "interlúdio weberiano", na opção de Max Weber pelo termo "ética" (e não ideologia) protestante.

Acolhendo a hipótese habermasiana de uma relação emancipadora entre "conhecimento e interesse", pode-se dizer que uma das motivações que imantam o esforço teórico desenvolvido nesse livro é o desejo de adensar a resistência ao "liberalismo econômico puro e duro", que recrudesceu consideravelmente nas últimas décadas do século XX. Seria legí- timo dizer, portanto, que se trata de um projeto "contraideológico", e sua contribuição entre nós se fará sentir tanto nos estudos sociológicos como literários (por exemplo, na árdua tarefa de destrinçar "nós ideológicos" em obras do porte das Memórias póstumas). Entende-se daí a relevância que o autor dispensa ao pensamento - e, mais ainda, à práxis de figuras como Gramsci e Simone Weil, aproximadas justamente numa chave de resistência. Pelo lado brasileiro, a empatia de Bosi faz avultar Joaquim Nabuco e Celso Furtado, aos quais são dedicados dois dos mais belos ensaios. Como perceberá o leitor, nesse livro que abrange tão vasto material teórico e histórico, a clareza da exposição encontra-se intimamente conjugada com a atenção ao fato concreto (a verità effettuale della cosa encarecida por Maquiavel) e a tendência a sempre historicizar concepções e ações das figuras enfocadas, conforme se mostra exemplarmente em relação a nomes como Perdigão Malheiro e Tavares Bastos, já antes enaltecidos por Nabuco.

É claro que, em face de um trabalho de tão amplo espectro, pode-se apontar para uma ou outra lacuna, fazer essa ou aquela ressalva etc. Um possível exemplo: Ernst Bloch é mobilizado, ao lado de Walter Benjamin, na argumentação aliás, plenamente legítima - que procura mostrar o lado "desalienante" da religião; contudo, essa tarefa seria mais dificultosa se fosse considerado (pois também contraideologias e utopias não estão isentas de contradições) que Bloch, o filósofo do "princípio-esperança” e do "ainda não", foi um dos mais veementes defensores do estalinismo. E já que os dois últimos ensaios da primeira parte são dedicados ao "projeto fáustico" e ao Fausto de Goethe, seria cabível uma referência a Oswald 
Spengler, que em sua obra de inspiração nietzschiana $A$ decadência do Ocidente caracterizou pioneiramente o homem ocidental, em sua incansável aspiração por transformar o mundo e expandir fronteiras, como "fáustico", contrapondo-o ao homem "apolíneo" da Antiguidade, voltado tão somente ao presente e, assim, alheio à dimensão do passado e do futuro. Mas semelhantes objeções ou eventuais lacunas que se possam verificar nessa incursão de Alfredo Bosi pela espinhosa história do conceito de ideologia serão afinal irrelevantes diante dos seus inúmeros méritos, entre os quais está o de aguçar a percepção do leitor para aquilo que Paul Ricouer chamou de "clausura ideológica" (clôture idéologique).

Marcus V. Mazzari é professor de Teoria Literária e Literatura Comparada na USP, tradutor e também autor, entre outros, de Labirintos da aprendizagem - Pacto fáustico, romance de formação e outros temas de literatura comparada (Editora 34, 2010). Elaborou os prefácios, comentários e notas aos volumes Fausto I (Editora 34, 2004 - edição revisada e ampliada: 2010) e Fausto II, de Goethe (Editora 34, 2007), em tradução de Jenny Klabin Segall. @-mazzari@usp.br 